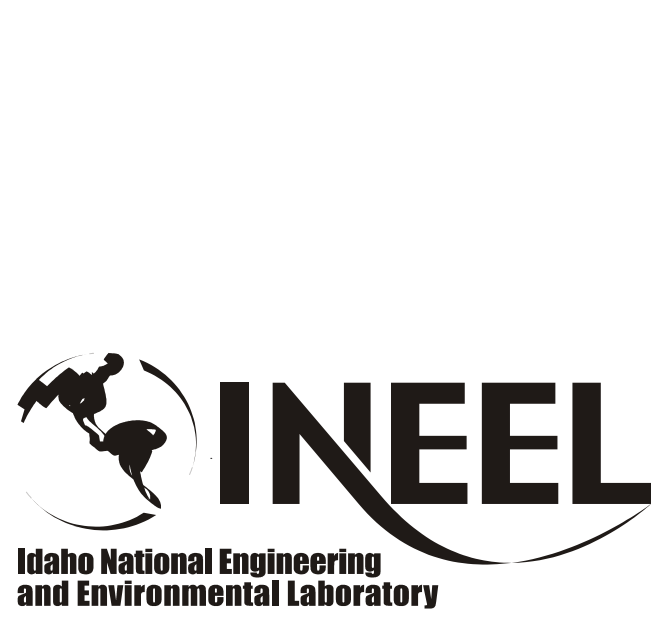

Idaho National Engineering and Environmental Laboratory
INEEL/CON-02-01400

PREPRINT

\section{Two CdZnTe Detector-Equipped Gamma-ray Spectrometers for Attribute Measurements on Irradiated Nuclear Fuel}
J. K. Hartwell
P. L. Winston
D. J. Marts
L. D. Moore-McAteer
S. C. Taylor

April 7, 2003 - April 11, 2003
This is a preprint of a paper intended for publication in a journal or proceedings. Since changes may be made before publication, this preprint should not be cited or reproduced without permission of the author.

This document was prepared as a account of work sponsored by an agency of the United States Government. Neither the United States Government nor any agency thereof, or any of their employees, makes any warranty, expressed or implied, or assumes any legal liability or responsibility for any third party's use, or the results of such use, of any information, apparatus, product or process disclosed in this report, or represents that its use by such third party would not infringe privately owned rights. The views expressed in this paper are not necessarily those of the U.S. Government or the sponsoring agency. 


\title{
Two CdZnTe Detector-Equipped Gamma-ray Spectrometers for Attribute Measurements on Irradiated Nuclear Fuel
}

\author{
J. K. Hartwell", P. L. Winston, D. J. Marts, L. D. Moore-McAteer, and S. C. Taylor \\ Idaho National Engineering and Environmental Laboratory \\ PO Box 1625 \\ Idaho Falls, ID 83415 \\ USA \\ "Corresponding author \\ John K. (Jack) Hartwell \\ Idaho National Engineering and Environmental Laboratory \\ PO Box 1625 MS 2114 \\ Idaho Falls, ID 83415-2114 \\ V-208-526-9366 Fax-208-526-9267 \\ jkh2@inel.gov
}

\begin{abstract}
Some United States Department of Energy-owned spent fuel elements from foreign research reactors (FRRs) are presently being shipped from the reactor location to the US for storage at the Idaho National Engineering and Environmental Laboratory (INEEL). Two cadmium zinc telluride detectorbased gamma-ray spectrometers have been developed to confirm the irradiation status of these fuels.

One spectrometer is configured to operate underwater in the spent fuel pool of the shipping location, while the other is configured to interrogate elements on receipt in the dry transfer cell at the INEEL's Interim Fuel Storage Facility (IFSF) Both units have been operationally tested at the INEEL.
\end{abstract}

\section{Introduction}

United States Department of Energy-owned spent fuel elements from foreign research reactors (FRRs) are presently being shipped from the reactor location to the US for storage. ${ }^{1}$ Some of these shipments are destined for the Idaho National Engineering and Environmental Laboratory (INEEL). Shipments are secured with tamper indicating devices (TIDs) at the shipping locations, and are accompanied with documentation of the power history and cooling time of the elements. Two gammaray spectrometers equipped with cadmium zinc telluride $(\mathrm{CdZnTe})$ detectors have been developed to acquire the gamma-ray spectral data required to measure fission product content ratios that can be compared with those calculated from the operator-declared burn up and cooling times. One spectrometer is configured to operate underwater in the spent fuel pool of the shipping location, while 
the other is configured to interrogate elements on receipt in the dry transfer cell at the INEEL's Irradiated Fuel Storage Facility (IFSF.)

While the underwater gamma-ray spectrometer (TUGS) has not been fielded for FRR shipment measurements, it was tested in a fuel storage basin at CPP 603 to elucidate the contents of certain high dose rate objects found on the basin floor in past years. The in-cell examination system (ICES), that in addition to the gamma-ray spectrometer, incorporates equipment for video inspection, gamma-ray dose rate measurements, and laser-based range determination, has been installed in the dry transfer cell of the Irradiated Fuel Storage Facility (IFSF) and has undergone preliminary testing.

\section{Gamma-ray detectors and electronics}

Although different in their shielding design and applications, the gamma-ray spectrometers of both the ICES and TUGS units are similar. The eV Products-supplied detectors are $5 \mathrm{X} 5 \mathrm{X} 5 \mathrm{~mm}^{3} \mathrm{CdZnTe}$ detectors. The detectors are quasi-hemispherical devices with a full area anode and extended cathode that provides improved charge collection characteristics and thus improved resolution and peak shape relative to a pure planar design. ${ }^{2}$ The detectors are packaged along with a hybrid preamplifier in an integral package $12 \mathrm{~mm}$ in diameter and $89 \mathrm{~mm}$ in length.

The gamma-ray spectrometric electronics for both systems were Canberra Inspector 2000 portable digital spectroscopy workstations running identical gain and filter parameter settings. The system gain was set to provide about $2000 \mathrm{keV}$ full scale in a 2048 channel spectrum. The trapezoidal digital filter parameters were a rise time and fall time of $1.2 \mu \mathrm{s}$ and a flat top width of $0.6 \mu \mathrm{s}$. This is roughly equivalent to $0.5 \mu$ s semi-Gaussian shaping. With these parameters both detectors exhibited a nominal

resolution full width at half maximum (FWHM) of $11 \mathrm{keV}(1.7 \%)$ for the $661.5 \mathrm{keV}$ line of ${ }^{137} \mathrm{Cs}$. The peak channel-to-valley (at centroid minus 5XFWHM) ratio was about 6.0:1. Data acquisition and spectral analysis functions were provided by Canberra's GENIE 2000 software. 


\section{The underwater gamma-ray spectrometer (TUGS)}

\section{Design}

The underwater gamma-ray spectrometer (TUGS) was designed for possible deployment at FRR shipping locations to augment TRIGA fuel element inspections. Prior to packaging for shipment, irradiated FRR TRIGA fuel elements are subjected to a video examination and tested for straightness using an examination "jig." TUGS was developed to mate to the examination jig and acquire attribute information on the irradiated element's fission product inventory prior to shipment.

The underwater portion of TUGS is housed in a stainless steel dry tube about 1 meter long and 19 $\mathrm{cm}$ in diameter. The dry tube contains the $\mathrm{CdZnTe}$ detector, shielding and a rotating collimator along with a suite of stepping motors and encoders to implement positioning control. In order to extend the dynamic range of the spectrometer over the full range of fuel activities expected, TUGS is equipped with both remotely selectable collimation and adjustment of the source-to-detector distance. A cutaway drawing of the TUGS measurement head is presented in Figure 1. Figure 2 is a photograph of the assembled TUGS measurement head with the dry tube removed. Figure 3 shows the unit and the dry tube.

All of the TUGS shield and collimator components are fabricated from a tungsten alloy $(89.9 \% \mathrm{~W}$ by weight). The shield design places the CdZnTe detector at the center of a closed right circular shield $7.6 \mathrm{~cm}$ thick on its front face, $7.1 \mathrm{~cm}$ thick on the sides, and $5 \mathrm{~cm}$ thick at the rear. Connection cables to the detector run through a Z-shaped access channel at the rear of the shield. The front shield face accommodates the collimator through a stepped hole offset from the center axis of the cylindrical shield.

The TUGS collimator is a stepped right circular cylinder sized to fit the hole in the front shield. The $7.6 \mathrm{~cm}$ long collimator is penetrated by three holes $2 \mathrm{~mm}, 3 \mathrm{~mm}$, and $5 \mathrm{~mm}$ in diameter. The collimator apertures are spaced so that any of the three apertures can be rotated into position for measurements. A 
remotely-controlled stepping motor, located at the rear of the shield, drives the collimator through a shaft and gear arrangement. An encoder reads the collimator position, and transmits it to the operator. The front flange of the dry tube within the collimator view was milled to a thickness of about $0.3 \mathrm{~cm}$ to decrease the attenuation of low energy photons.

For additional control over the spectrometer input rate, the entire detector shield and collimator package can be moved forward and backward on a set of rails within the dry tube. A stepping motor driven linear actuator and encoder provide position control and readout. The linear system provides about $32 \mathrm{~cm}$ of linear travel.

The required control, high voltage, signal and data cables exit the TUGS dry tube through watertight connectors. The cables are water-resistant cables about 16 meters long.

\section{Testing and Calibration}

The adequacy of TUGS collimation and shielding was tested at the INEEL's Health Physics Instrumentation Laboratory (HPIL). The HPIL has a nominally $17 \mathrm{TBq}(450 \mathrm{Ci}){ }^{137} \mathrm{Cs}$ calibration facility that, through remote positioning, can deliver gamma-ray dose rates up to $3.40 \mathrm{~Gy} / \mathrm{hr}(340 \mathrm{R} / \mathrm{hr})$ to items in its irradiation position. The TUGS unit (without linear rails and dry tube) was positioned at the irradiation position and tested for shield integrity at dose rates up to $3.0 \mathrm{~Gy} / \mathrm{hr}$. With the smallest (2 $\mathrm{mm}$ ) aperture selected, the system dead time registered less than $50 \%$ at the highest tested dose rate of 3.0 Gy/hr. More importantly, when the collimator was rotated to a blank (no aperture) position, the dead time dropped to about $3 \%$, and no $662 \mathrm{keV}{ }^{137} \mathrm{Cs}$ peak was detected in a 500 second counting interval. An important design criterion for TUGS was that the shield integrity be sufficient to provide a ratio of signal (count rate through the smallest collimator) to "background" (count rate through the "blank" position) of $\geq 540$ for $662 \mathrm{keV}$ gamma rays at a dose rate of $1 \mathrm{~Gy} / \mathrm{hr}$. The measured ratio for this unit was $\geq 30,000$ in tests at $3 \mathrm{~Gy} / \mathrm{hr}$. 
The TUGS objective of determining fission product activity ratios requires only a relative rather than absolute photopeak efficiency calibration. However, an opportunity arose to deploy TUGS here at the INEEL in an application that required an absolute efficiency calibration in order to estimate the fission product activity of certain legacy items in one of our spent fuel storage basins. Consequently, absolute photopeak efficiency versus energy curves were determined at each TUGS collimator aperture at three selected linear rail positions (fully forward, midpoint, fully retracted). The curves were developed from spectra acquired on a calibrated point source of ${ }^{152}$ Eu carefully centered in the collimator view at a collimator-to-source distance of about $13 \mathrm{~cm}$ and contained in a stainless steel container identical to that housing the legacy item. The activity of the calibration source was sufficient to provide an adequate ( $\pm 20 \%$ relative standard deviation) efficiency curve over the energy range from about $100 \mathrm{keV}$ to 1400 $\mathrm{keV}$ at the most sensitive combination of a $5 \mathrm{~mm}$ diameter collimator aperture and the shortest sourceto-collimator distance. Efficiency values for the less sensitive combinations of collimator aperture and linear position were estimated by adjusting this measured curve by the relative ratios of the integral stored net rate measured at each geometry. These measurements resulted in a family of curves of absolute photopeak efficiency $(\mathrm{c} / \gamma)$ versus gamma-ray energy $(\mathrm{keV})$. The photopeak efficiency at 662 $\mathrm{keV}$ varied from $(9.9 \pm 2.6) \mathrm{E}-11 \mathrm{c} / \gamma$ for the $2 \mathrm{~mm}$ aperture and a fully retracted $(32 \mathrm{~cm})$ collimator and shield, to $(1.1 \pm 0.2) \mathrm{E}-08 \mathrm{c} / \gamma$ at the most sensitive position ( $5 \mathrm{~mm}$ aperture and fully forward).

\section{Underwater deployment}

The spent fuel storage basins at the INEEL's CPP603 building have been defueled in preparation for decontamination and decommissioning (D\&D). Five "legacy" items, termed generic fuel objects (GFOs), that had been retrieved from the basin floor over its decades of operation had to be dispositioned in order to facilitate D\&D. When retrieved, they could not be identified. Thus, each had been placed in separate storage canisters and stored in the basin. TUGS was recruited to elucidate the 
contents of these items. The hope was that TUGS would find them to be activated metals with no indication of fuel material and thus they could be discarded as low level waste.

One of these items (GFO-1) was a right circular aluminum cylinder about $3.2 \mathrm{~cm}$ OD by $18 \mathrm{~cm}$ long. It had been the subject of autoradiographic, eddy current, and weight studies to gain information on its contents. The internal volume of the cylinder was estimated as $2.46 \mathrm{~cm}$ by $17.1 \mathrm{~cm}$ and its contained weight calculated to be 308 grams. The radiograph showed the contents to be a highly radioactive item about $1 \mathrm{~cm}$ in diameter by about $17 \mathrm{~cm}$ in length.

The remaining 4 items (GFOs 2 through 5) were visually similar and resembled metal "clips" of some sort. They were parallelepipeds about $3.8 \mathrm{~cm} \mathrm{X} 7.6 \mathrm{~cm} \mathrm{X} 1.3 \mathrm{~cm}$, each weighing about 237 grams with a density very close to that of stainless steel.

TUGS was fitted with positioning rings on its front flange to center the standard storage canisters that held these items. The TUGS underwater head was positioned in the pool on top of a submerged fuel rack with its front flange protruding over the rack edge. The GFO-containing canisters were sequentially moved by crane from their basin storage locations and lowered through the TUGS positioning rings. A series of vertical crane "jogs" and hook rotations positioned each item to maximize the spectrometer counting rate. When properly positioned, gamma-ray spectra were acquired on GFO-1, GFO-2, and GFO-3.

The gamma-ray spectra on GFOs 2 and 3 (the metal clip-appearing items) showed ${ }^{60} \mathrm{Co}$ as the only detectable radionuclide. This is consistent with activated stainless steel. GFOs 4 and 5 were not measured, but were assumed to be identical to GFO-1 and -2 .

The gamma-ray spectra acquired on GFO-1 (the aluminum cylinder) is presented in Figure 4. Detected photons included those of fission product ${ }^{137} \mathrm{Cs}(662 \mathrm{keV})$ along with prominent X-rays at 60 to $70 \mathrm{keV}, 98 \mathrm{keV}$ and $111 \mathrm{keV}$. The 60 to $70 \mathrm{keV}$ X-ray complex are those of fluorescence-excited 
emissions from the tungsten shielding. The $\mathrm{X}$-rays at 98 and $111 \mathrm{keV}$ are $\mathrm{K}$ x-rays from uranium.

Based on the history of fuel forms stored in this basin, these x-rays are from fluorescence excitation in uranium rather than decay-produced X-rays from plutonium decay.

Based on the TUGS spectral results, GFO-2,3,4, \&5 were discarded as low-level waste. However, GFO-1 was transported to a storage location in an operating spent fuel storage basin at the INEEL where it is managed as an irradiated fuel form.

\section{The in-cell examination system (ICES)}

\section{Design}

The in-cell examination system (ICES) was designed and built to examine irradiated fuels moving through the IFSF dry transfer cell on their way to interim storage. ICES incorporates a shielded and collimated CdZnTe detector-based gamma-ray spectrometer, a low range $(0-2 \mathrm{~Sv} / \mathrm{hr})$ and a high range $(0$ - $200 \mathrm{~Sv} / \mathrm{hr}$ ) ion chamber, a laser range finder (Acuity Research Accurange), and a radiation-hardened video camera (RJ Electronics RCS-510) with tilt and zoom. The ion chambers are partially collimated to peak their responses to items located in front of the unit. Figure 5 presents annotated photos of the ICES prior to installation in the cell. Figure 5 (a) is a front view, while 5 (b) is a view from the side.

In ICES, the CdZnTe detector lies at the approximate center of a 33-cm diameter by $40-\mathrm{cm}$ long right circular cylinder of bismuth. The shield unit was designed to accept three remotely replaced tungsten collimators. The available collimator apertures were $10 \mathrm{~mm}, 3 \mathrm{~mm}$ and $1 \mathrm{~mm}$ diameters. The collimator depth is approximately $150 \mathrm{~mm}$. Collimators are changed manually using a remote manipulator. The CdZnTe detector of the ICES was calibrated for relative photopeak efficiency response prior to installation into the unit. (Since the function of this instrument was determination of isotopic ratios rather than absolute activities, an absolute calibration was not required.) 
The laser range finder is mounted in a shielded box mounted behind the spectrometry detector's bismuth shield to minimize damage to the electronics by high radiation fields. The range finder axis is parallel to the axis of the ion chambers. The beam is directed from a 90-degree mirror to eliminate direct exposure of the return sensor to direct radiation. The unit measures the distance (up to 55 feet) from the source to the detector so that contact dose values can be calculated.

The shielded, radiation-hardened video camera provides a view of the fuel being assayed. The zoom feature allows confirmation of item serial numbers and cladding integrity.

The whole set of sensors (gamma spectrum, gross gamma, laser range finder, and camera) are mounted as a unit that can be rotated through about $270^{\circ}$ by operating an electrically-driven rotary table to point at a fuel item suspended from a handling tool. Being able to "aim" the item allows a high degree of flexibility with respect to where measurements can be taken during a fuel handling cycle.

\section{Testing}

The ICES unit was installed in the fuel transfer cell of the INEEL's Irradiated Fuel Storage Facility (IFSF). The ICES was initially hot tested during repackaging of fuel received from the Heidelberg II TRIGA reactor in Heidelberg Germany. The Heidelberg II fuel was received in June 2001, and the primary standard core was transferred by basket to IFSF storage canisters. The majority of the core was standard stainless steel TRIGA fuel that prior to shipping was put into open-top cans sized to fit the IFSF storage canisters. Each can contained four elements.

The individual fuel elements that were separate from these canned elements were two aluminum standard fuel elements and four fuel-follower control rods (FFCR). These elements did not fit into the standard cans and had to be moved into special baskets for the IFSF canisters. As these elements were handled separately in the IFSF transfer cell, they were available for ICES measurements with minimal impact on the fuel handling operations. 
The first fuel measured was an aluminum standard TRIGA element with very low burn up (about 0.3 atom \%.) For operational reasons this item was measured at a distance of approximately 3 meters. The low range ion chamber measured a gross gamma reading of $2 \mathrm{mSv} / \mathrm{hr}$, but the gamma-ray spectrum showed no peaks. Video inspection showed indications of corrosion in the fuelled area, with a slightly raised white pattern that is presumed to be aluminum oxide. A second standard aluminum element was measured at a distance of about 1.2 meters, the ion chambers recorded a dose rate of $5 \mathrm{mSv} / \mathrm{hr}$ and the gamma-ray spectrum showed a peak from fission product ${ }^{137} \mathrm{Cs}$ but no additional peaks for ratio calculations. Four additional elements were assessed. These were SS-clad FFCR elements measured at distances of about 1 meter. The ion chamber readings ranged from $22 \mathrm{mSv} / \mathrm{hr}$ to $33 \mathrm{mSv} / \mathrm{hr}$; however, the ICES operators misaligned the fuel elements so that the fueled region was above the spectrometer viewing aperture. The collimator aperture was actually aligned with the stainless steel plug just below

the fueled region of the FFCR elements. The spectrum analysis showed peaks from the ${ }^{60} \mathrm{Co}$ activation product of stainless steel, and no fission product peaks. A more positive alignment feature is being implemented as a system upgrade. However, analysis of the ICES-acquired gross gamma-ray dose rates showed a very good correlation between the operator-reported burn up and the measured value. ${ }^{3}$

\section{Summary and conclusions}

The underwater gamma spectrometer (TUGS) and the in-cell examination system (ICES) are complimentary systems for confirmatory measurements on DOE-owned irradiated fuels. Both systems have undergone test deployments that confirmed their operation and in some cases identified required upgrades. The room temperature solid-state $\mathrm{CdZnTe}$ detectors deployed in these systems gave adequate performance without the complications of cryogenic cooling. 


\section{Acknowledgements}

The operations and supervisory staff of the INEEL's Spent Nuclear Fuels Operations provided valuable assistance in the implementation and testing of TUGS and ICES. The expert and timely assistance of the INEEL's Prototype Shops in the design and fabrication of these units is gratefully acknowledged. The resources, support, and advice received from the staff of the INEEL's Safeguards and Security organization materially contributed to the success of this work. This work was performed for the US Department of Energy, Assistant Secretary for Environmental Management, under DOE Idaho Operations Office Contract DE-AC07-99ID13727.

\section{References}

${ }^{1}$ US DOE, 1996, DOE-Owned Spent Nuclear Fuel Strategic Plan, M94-GT-0535, Rev. 1, Sept. 1996

${ }^{2}$ K. PARNHAM, J. B. GLICK, Cs. SZELES, K. G. LYNN, Journal of Crystal Growth, 214/215 (2000) 1152.

${ }^{3}$ P. L. WINSTON, AND J. W. STERBENTZ, Gross Gamma Dose Rate Measurements for TRIGA Spent Nuclear Fuel Burn Up Validation, Proceedings of $10^{\text {th }}$ International Conference on Nuclear Engineering (ICON-10), Arlington, VA, April 14-18, 2002.

\section{Figure Captions}

Fig. 1. Cutaway depiction of the underwater gamma-ray spectrometer (TUGS) with key features labeled Fig. 2. TUGS measurement head with the dry tube removed.

Fig. 3. TUGS measurement head ready to be inserted into the dry tube.

Fig. 4. A spectrum acquired (4662 live time seconds) underwater with GFO-1 positioned in front of the TUGS unit. The medium collimator aperture $(3 \mathrm{~mm})$ and mid-point rail position $(19 \mathrm{~cm})$ were used.

Fig. 5. The In-Cell Examination System (ICES) with components identified. Figure 5 (a) is a view from the front of the unit, (b) is a side view 


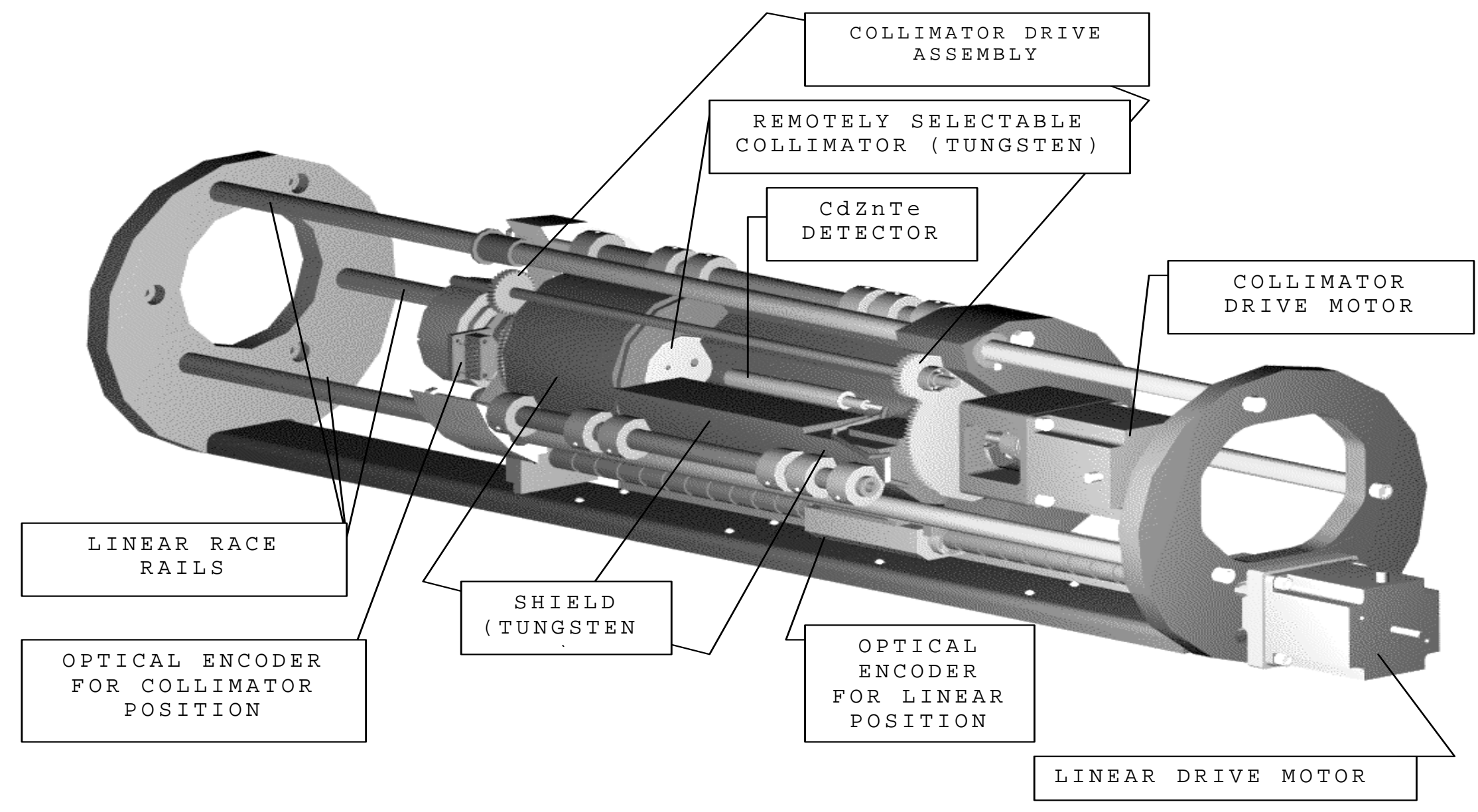

Figure 1. Cutaway depiction of the underwater gamma-ray spectrometer (TUGS) with key features labeled. 


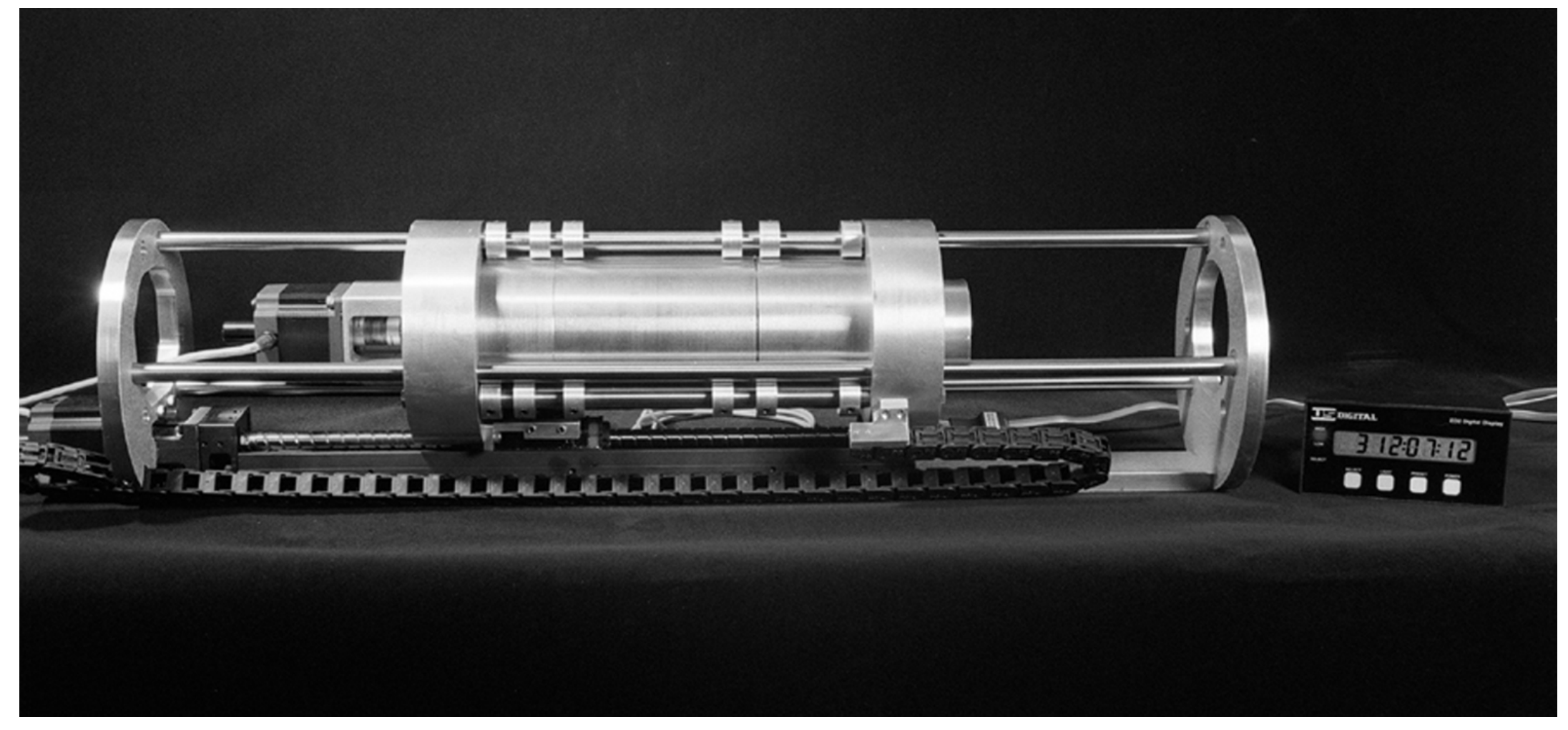

Figure 2. TUGS measurement head with the dry tube removed. 


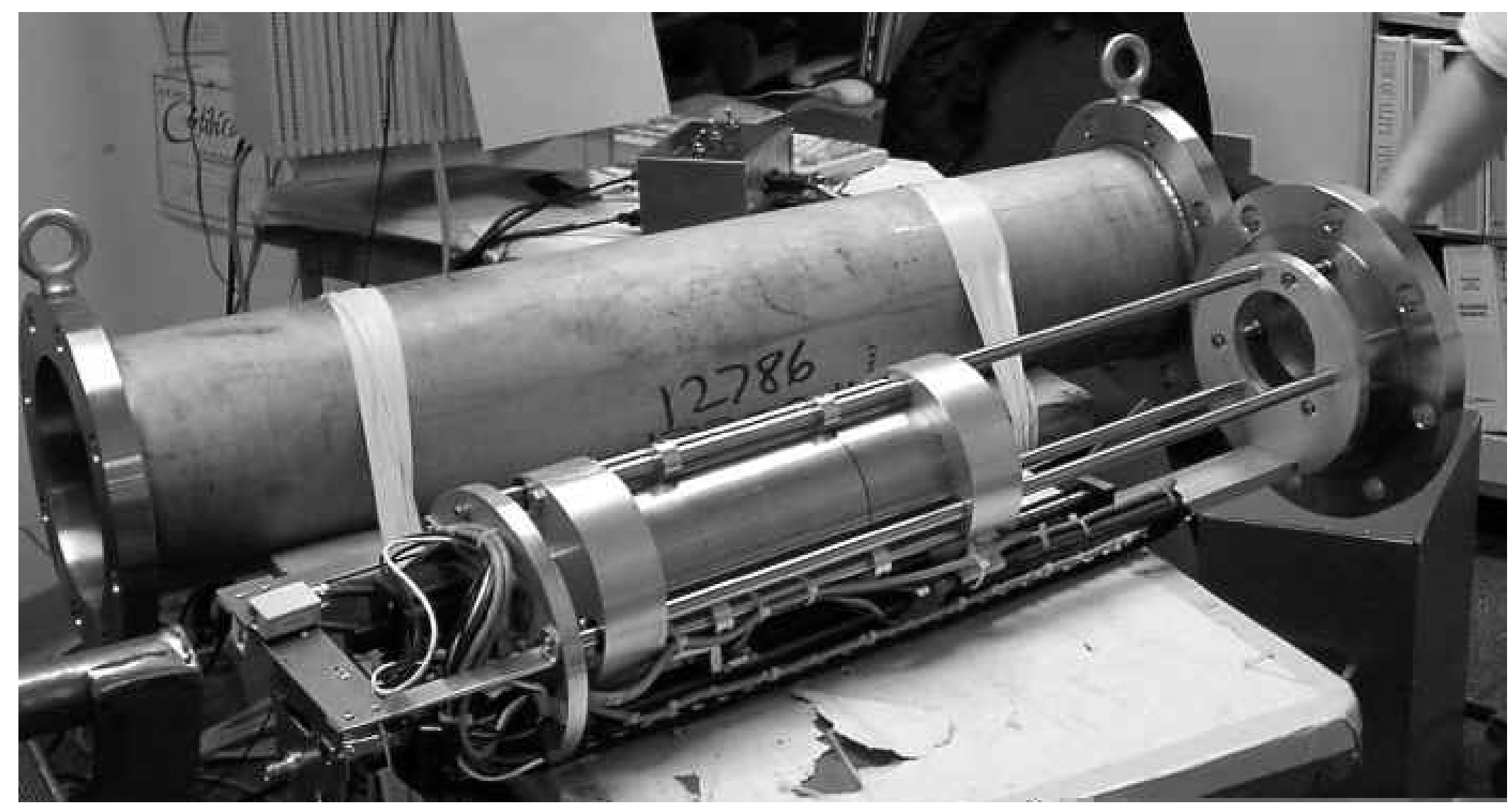

Figure 3. TUGS measurement head ready to be inserted into the dry tube. 


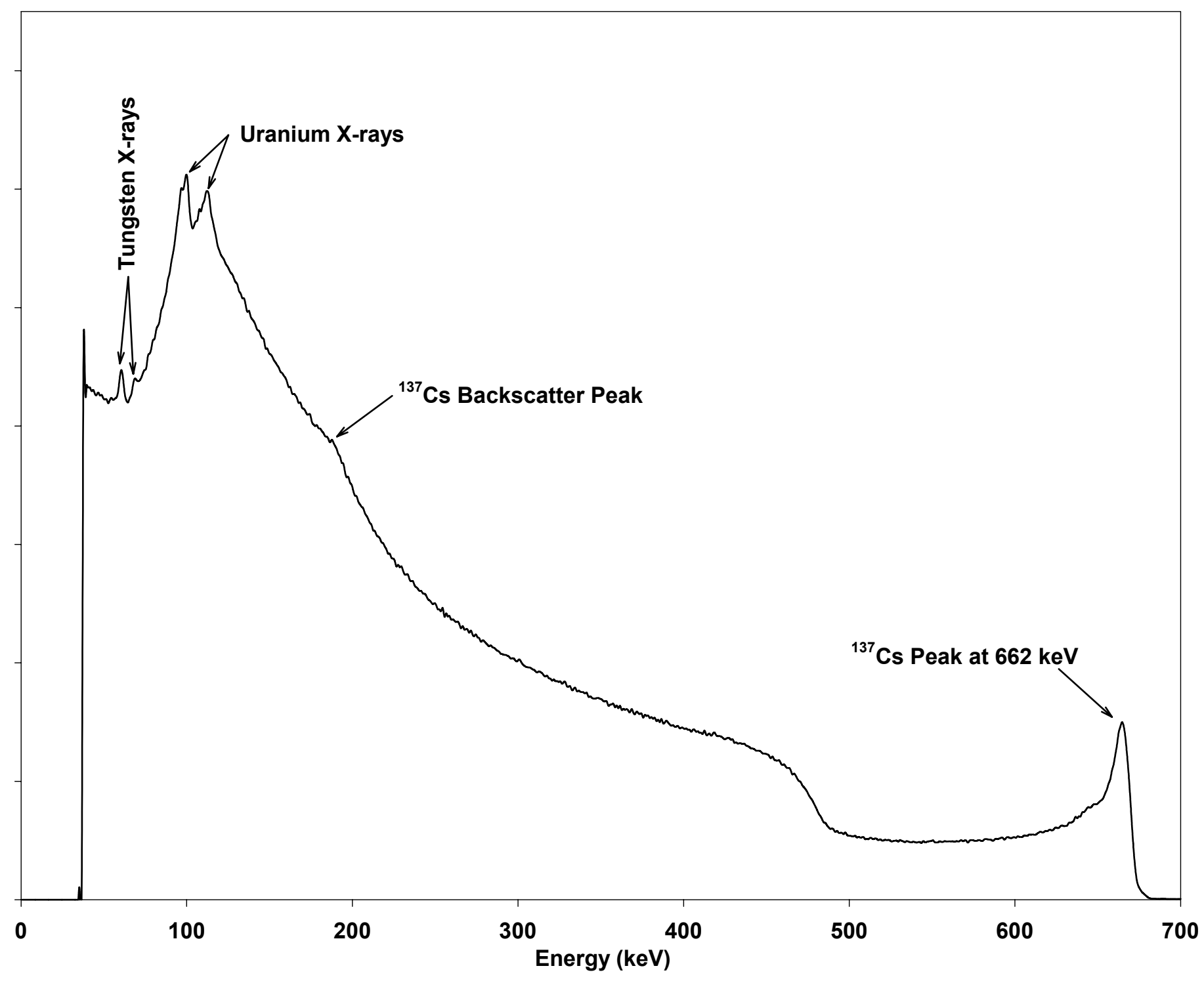

Figure 4. A spectrum acquired (4662 live time seconds) underwater with GFO-1 positioned in front of the TUGS unit. The medium collimator aperture $(3 \mathrm{~mm})$ and mid-point rail position $(19 \mathrm{~cm})$ were used. 


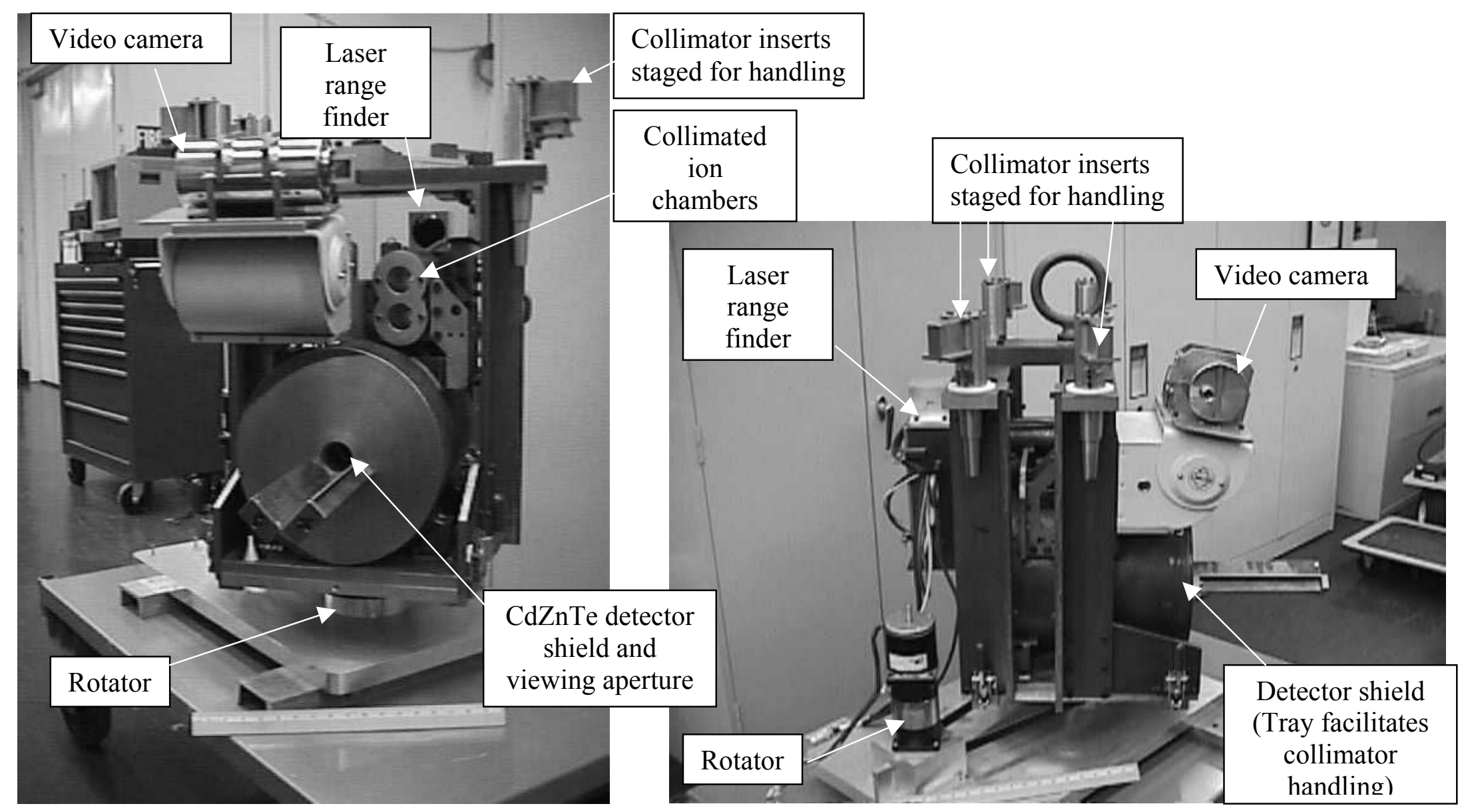

Figure 5. The In-Cell Examination System (ICES) with Components identified. Figure 5 (a) is a view from the front of the unit, (b) is a side view. 